\title{
СОВРЕМЕННЫЕ МОДЕЛИ ФОРМИРОВАНИЯ СУДЕЙСКОГО КОРПУСА В ЗАРУБЕЖНЫХ СТРАНАХ
}

Аннотация: Предметом исследования являются современные зарубежные системы формирования судейского корпуса. Национальные модели комплектования судей отличаются друг от друга по своим способам, критериям и этапам отбора кандидатов на вакантные судейские должности. Их особенности сложились в результате исторического развития и в зависимости от конституционного строя, территориального устройства страны, социально-культурного и экономического контекста. Выявление наиболее совершенных систем отбора и наделения судей полномочиями, которые позволяют осуществлять комплектование судов лучшими судьями, является политико-правовой и научной задачей. В работе проводится классификация современныхмоделей комплектования судейского персонала. В качестве классификационного признака использован способ отбора и наделения полномочиями судей, под которым понимается установленная система мероприятий комплектования персонального состава судов. В работе сделан вывод об отборе на основании заслуг как преимущественном типе формирования судейского корпуса в современный период по сравнению с выборами судей. В работе прослеживается эволюция методов формирования судейского корпуса в США. Утверждается, что большинство европейских стран используют систему конкурсного отбора судей на основании заслуг. В результате анализа имеющихся практик выделен ряд проблемных вопросов, требующих дальнейшей модификации моделей конкурсного отбора, в том числе связанных с определением критериев конкурсного отбора и способами их экспертной оценки.

Ключевые слова: Формирование судейского корпуса, способ, критерии отбора, кандидат в судьи, модели, лучиие практики, отбор по заслугам, конкурсный отбор, выборы судей, назначение судей.

Abstract: The subject of this research is the modern foreign systems of formation of the judiciary. The national models of recruitment of judges differ in their methods, criteria and the stages of selection of candidates for vacant judicial posts. Their features were formed as a result of historical development, and depending on the constitutional order, the territorial structure of the country, socio-cultural and economic context. Political, legal and scientific challenge is to identify the most perfect system of selection and appointment of judges, which would ensure the appointment of judges from the best available candidates. This work deals with the classification of modern models of recruitment of judicial personnel. As a classification attribute, the author examines the established system of methods of selection and appointment of judges. Among the conclusions is the fact that the merit selection is the predominant type of formation of the judiciary in the modern period compared with the election of judges. The paper traces the evolution of methods of formation of the judiciary in the United States. It is argued that most European countries use a system of competitive selection of judges on the basis of merit. An analysis of existing practices identified a number of problematic issues that require further modification of competitive selection models, including those associated with the definition of competitive selection criteria and processes for their expert evaluation.

Keywords: Best practices, models, candidate for the post of judge, criteria for selection, method, formation of the judiciary, merit selection, competitive selection, election of judges, appointment of judges.

современных зарубежных правовых системах наблюдается большое разнообразие существующих подходов к организации и процессу комплектования судейского корпуса. Национальные модели подготовки и рекрутирования судей отличаются друг от друга по своим способам, критериям и этапам отбора кандидатов на вакантные судейские должности. Существующие модели формирования судейского корпуса являются результатом исторического развития государств, зависят от конституционного строя, территориального устройства страны, особенностей ее социально-культурного и экономического контекста.
Вопросы формирования судейского корпуса, включая способ и содержание, составляют неотъемлемую часть государственной судебной политики, определяются существующими в стране политико-правовыми и философско-правовыми взглядами и тесно с ними взаимосвязаны.

Поиск наиболее совершенных систем отбора и наделения судей полномочиями преследует цель комплектования судов лучшими судьями.

Названная цель обуславливает исследовательские задачи по выявлению лучших мировых практик формирования судейского корпуса, что предполагает необходимость классификации существующих в зарубежных 
странах разновидностей систем отбора и наделения судей полномочиями. В качестве классификационного признака в настоящей работе будет использован способ (в западной литературе чаще именуемый как метод) отбора и наделения полномочиями судей, под которым понимается установленная система мероприятий, процедура комплектования персонального состава судов.

В отечественной юридической науке в зависимости от указанного признака выделяются следующие типы систем отбора и назначения судей: назначение судебной властью непосредственно, назначение юридическим сообществом (которое может включать представителей судебной системы), назначение судей политическими институтами, отбор судей на основе выборов [1].

В западноевропейской литературе к числу моделей формирования судейского корпуса в зависимости от указанного признака отнесены: назначение судей законодательной властью, назначение органами исполнительной власти, выборы на основе партийной принадлежности, беспартийные выборы судей, выбор на основании заслуг, предполагающий отбор независимой комиссией кандидатов в судьи и представление списка кандидатов уполномоченному для назначения лицу [2].

При анализе существующих в мировой практике способов отбора и назначения судей заметное место уделяется истории развития указанных методов в правовой системе Соединенных Штатов Америки. По мнению американских ученых и практиков, это объясняется заметным вкладом американского правительства в создание самостоятельной и независимой судебной власти, что позволило лучшие практики американской судебной системы заимствовать по всему миру [3].

В Соединенных Штатах Америки насчитывается почти столько же различных способов отбора и наделения полномочиями судей, сколько и самих штатов[3]. Основными способами судебного комплектования судов являются четыре: назначение органами исполнительной либо законодательной власти или губернатором, наделение полномочиями самим судейским сообществом, выборы по партийным спискам или на внепартийной основе, отбор кандидатов на основе их заслуг. Наряду с указанными, используется комбинация способов, что позволяет говорить о многих вариантах формирования судейского корпуса [4]. При этом в рамках одного штата могут действовать несколько способов одновременно, каждый из которых применяется к суду соответствующего уровня и компетенции [5].

В истории судоустройства переход от одного типа формирования судейского корпуса к другому в самом общем виде был результатом ответных шагов на возрас- тание требований в отношении более профессионального и менее политически зависимого судейского сообщества. Проследим закономерности такого перехода на примере эволюции методов комплектования судов в США.

Исторически первым способом комплектования судейского персонала является назначение судей по собственному усмотрению соответствующим должностным лицом (например, губернатором штата) или компетентным органом (например, органом законодательной власти). Особенно активно метод назначения судей стал заменяться всенародными их выборами в период правления Э. Джексона (1827-1834 гг.), когда демократизация достигает широкого размаха. Выборы судей позволяли последним более чутко реагировать на потребности населения в правосудии, обеспечивали подотчетность судей обществу, что являлось более предпочтительным по отношению к системе назначения по усмотрению.

Однако выборы судей изначально строились на партийной основе, как и все другие процессы народного избрания должностных лиц. В рамках партийных выборов судьи избирались не по профессиональным критериям, а по партийной принадлежности. Это позволяло при поддержке лидирующей партии переигрывать аспекты квалификации кандидата, его опыта и образования.

Указанные недостатки выборной системы по партийным спискам стали устраняться выборами судей на беспартийной основе. Но недостатки избирательного процесса, характерные для любых выборов, не позволяли считать цель судебных выборов - отбор лучших кандидатов в судьи - достигнутой. К таким недостаткам относились: необходимость предвыборной агитации и обещаний электорату, что могло порождать сомнения в беспристрастности судей впоследствии; необходимость нести расходы по финансированию избирательной кампании, что ограничивало доступ к профессии судьи всех юристов, которые по своим профессиональным качествам могли бы ими стать.

Способ отбора кандидатов в судьи на основании их заслуг, известный также как Миссурийский план, был разработан в 1913 году как компромисс, который объединил лучшие черты назначения и избрания. Этот способ именуется в зарубежный литературе «merit selection» [6], который является, по сути, гибридом, позволяющим сгладить отрицательные черты ранее апробированных способов комплектования судов и объединить их сильные стороны. Метод «merit selection» предполагает отбор кандидатов в судьи на основании их профессиональных качеств и достоинств независимой комиссией, состоящей из представителей законодательной и исполнительной властей, но где большинство членов представлены самими судьями. Такая комиссия, используя заранее 
DOI: $10.7256 / 1811-9018.2015 .3 .14433$

При цитировании этой статьи сноска на доі обязательна

\section{Право и политика $3(183) \cdot 2015$}

известные процедуры и методы исследования заслуг кандидатов, дает рекомендацию некоторым из них, как правило, не менее двух, отвечающим всем предъявляемым требованиям. Рекомендации направляются губернатору штата или другому уполномоченному компетентному лицу (органу) для назначения кандидата на должность из представленного списка.

Метод отбора на основании заслуг является приоритетным в настоящий период в практике комплектования судейского корпуса в США. По состоянию на 2012 год в тридцати шести штатах США используется система отбора судей на основании заслуг, по крайней мере, в отношении комплектования некоторых уровней судебной системы [7]. В пятнадцати штатах (Аляска, Аризона, Колорадо, Айова, Канзас, Небраска, Нью-Йорк, Оклахома, Род-Айленд, Южная Каролина, Южная Дакота, Теннеси, Юта, Вермонт, Вайоминг) данный способ формирования судейского корпуса применяется ко всем судьям всех судов $[4,8]$.

Зародившийся в начале прошлого века способ отбора судей на основании заслуг на протяжении ХХ века завоевывал признание в разных странах мира. На европейском континенте с конца XX-начала XXI вв. метод «отбора на основании заслуг», именуемый в европейских правовых актах как конкурсный отбор судей, признается стандартом формирования судейского корпуса, максимально обеспечивающий независимость судей (Европейская хартия о законе о статусе судей от 10 июля 1998 г., Рекомендация Комитета Министров Совета Европы CM/Rec (2010) 12 «O независимости, эффективности и ответственности судей» от 17 ноября 2010 г.).

Большинство европейских стран в качестве способа формирования судейского корпуса используют систему конкурсного отбора судей на основании заслуг (Бельгия, Болгария, Франция, Венгрия, Испания, Италия, Литва, Нидерланды, Польша, Португалия, Румыния, Словакия, Словения и др.). Выборная судейская система в современных правовых системах встречается редко [9, 10]. Российская Федерация, как и большинство европейских стран, в качестве способа формирования судейского корпуса использует систему конкурсного отбора судей на основании заслуг. В силу ч. 5 ст. 13 Федерального конституционного закона «О судебной системе Российской Федерации» отбор кандидатов на должности судей осуществляется на конкурсной основе.

Существенными признаками конкурсного отбора являются наличие таких критериев отбора, которые бы позволили комплектовать суды лучшими судьями.

Выделение зарубежных моделей формирования судейского корпуса, базирующиеся на анализе критериев конкурсного отбора соискателей в судьи, возможно в зависимости от: а) наличия универсальных или дифференцированных условий допуска кандидатов в судейский корпус; б) перечня позитивных требований, предъявляемых к кандидатам на должности судей и наличия запретов к занятию судейской должности, включая факторы позитивной дискриминации и коллизии интересов; в) использования в качестве приоритетного критерия конкурсного отбора профессионального ранжирования (рейтинга) кандидатов или применения в равной степени всех критериев отбора в совокупности; г) наличия или отсутствия досудебной подготовки кандидатов в судьи; д) наличие заранее определенных и публично доступных критериев отбора. Вполне возможны к использованию и другие классификационные признаки.

Любая прозрачная система отбора на основании заслуг должна исходить из определенных и заранее известных критериев отбора лучших соискателей для целей правосудия. Такие критерии включают в себя, в том числе, и формальные требования, установленные законом. В одних странах в отношении всех кандидатов устанавливаются единые требования к вхождению в судейскую профессию, не предполагающие особенностей, например, в отношении круга лиц с большим опытом работы и высокой квалификацией. В других странах законодательно закреплена идея рекрутирования кандидатов из разных профессиональных групп или с подтвержденной высокой квалификацией на разных условиях, что означает наличие не единого универсального, а дифференцированных путей комплектования судейского корпуса. В этом случае наблюдаются разные требования, предъявляемые к кандидатам, в зависимости от их предшествующего опыта, квалификации и рода занятий (напр., Польша, Франция).

В системе конкурсного отбора на основании заслуг важную роль играет представление о том, что считать заслугами претендента на судейскую вакансию. Важно определить, какие факторы, касающиеся кандидата на должность судьи, должны иметь приоритетное значение. Анализ критериев, положенных в основу отбора кандидатов на судейские должности, позволяет сделать вывод о том, что большинство стран в числе таких критериев закрепляет требования к гражданству, возрасту, образованию, профессиональному опыту (стажу) кандидата, его состоянию здоровья, деловым и морально-нравственным качествам. Закрепляются также требования, связанные с владением на достаточном уровне языком судопроизводства и прохождением воинской службы (Литва, Армения).

Современное законодательство многих стран Европы демонстрирует достаточно детальный перечень требова- 
ний к кандидатам на судейские должности, а также запретов, не совместимых с должностью судьи. В основе таких запретов лежат правила о невозможности быть судьей по соображениям, основанным на разумных представлениях о независимом, компетентном и беспристрастном судье. Во многих правовых системах находим указание на несовместимость судейской карьеры и наличия судимости или привлечения к уголовной ответственности, статуса судьи и политической деятельности. Однако в числе запретов в некоторых постсоветских государствах обнаруживаются запреты, связанные с идеологическими, а не рациональными началами. В числе таких запретов правила о люстрации (напр., Латвия,Украина).

По своей природе указанные ограничения, обнаруживаемые в ряде постсоветских стран, следует рассматривать как дискриминирующие препятствия, создающие запреты доступа к судейской профессии по идеологическим причинам. В этой связи они не могут быть поддержаны. С учетом указанного характера положений о люстрации среди исследователей правовой системы Латвии высказаны суждения о необходимости «шаг за шагом удалять» такие ограничения для кандидатов в судьи и «по истечении времени дистанцироваться» от них [2].

Система публичного конкурса (отбора на основании заслуг) исключает дискриминационные запреты, касающиеся допуска к судейской профессии, по мотивам происхождения, социального и финансового положения, расовой и национальной принадлежности, пола, отношения к религии, рода и характера занятий, политических или иных взглядов. Вместе с тем не являются дискриминационными факторы, порождающие сомнения в беспристрастности судей и являющиеся следствием конфликта интересов, а также учет отдельных факторов гендерного характера и установление для этого соответствующих квот. Установление так называемой позитивной дискриминации при отборе судей демонстрируют в настоящее время ряд европейских стран и государств на постсоветском пространстве. В их числе: правило о необходимости переходного (не менее пяти лет) периода после карьеры адвоката, нотариуса, судебного исполнителя и до назначения судьей (Франция) [9], учет полового (гендерного) равновесия с установлением соответствующих квот (Армения) [11].

Следует выделить системы комплектования судейских кадров, где не только закреплена развернутая структура критериев отбора кандидатов на вакантные судейские должности, но и установлена определяющая роль ранжирования кандидатов в зависимости от выявленной их квалификации на процесс отбора лучших претендентов (напр., Болгария).
Модели комплектования судейских кадров могут различаться в зависимости от того, предусмотрены ли в качестве обязательных требований сдача квалификационных экзаменов. В большинстве стран европейского континента, где наблюдается бюрократический тип судейской карьеры [12], в отличие от систем англосаксонской правовой традиции, такой экзамен предусмотрен.

Объективность конкурса нельзя представить без эффективных средств определения компетенций соискателей. Такие средства должны позволять устанавливать не только формально-юридические параметры кандидатов на судейские должности, но и их интеллектуальные и личные качества. В разных моделях конкурсного отбора наблюдаются разные подходы к закреплению соответствующих процедур и мероприятий, осуществляемых независимыми органами судейского сообщества. В качестве оценочных инструментов в разных странах используются: устные и письменные экзамены, рейтинги юридического сообщества, комментарии о кандидате, полученные от его коллег, общественные слушания и общественные оценки, рекомендации, поручительства за кандидата, интервью с кандидатом, информация о его кредитных историях, судимости и фактах привлечения к уголовной ответственности, иная информация о конфликте интересов, любые целесообразные исследования, проводимые самим независимым органом, по выяснению опыта, квалификации и личных качеств соискателя, в том числе с вызовом свидетелей по этому поводу.

Признавая метод отбора на основании заслуг более предпочтительным в современных условиях, нельзя обойти вниманием его проблемные стороны, предполагающие направления совершенствования данного метода.

Метод «merit selection» в большей степени гарантирует отбор по профессиональным, а не политическим соображениям, поскольку кандидаты оцениваются независимым органом, не принадлежащим к структурам исполнительной, законодательной властей и в состав которого входят высококвалифицированные юристы. Применение шкалы профессиональных критериев отбора позволяет достичь большего разнообразия представителей разных юридических профессий в судейском сообществе, а также демографического, этнического и гендерного разнообразия. Вместе с тем добиться абсолютной технократичности процесса оценки и отбора по профессиональным качествам претендентов вряд ли возможно. В качестве проблемных представляются следующие важные вопросы: можно ли четко определить набор компетенций, по которым кандидаты для назначения на судейские должности должны быть оценены на всех этапах процесса назначения и зара- 
DOI: $10.7256 / 1811-9018.2015 .3 .14433$

При цитировании этой статьи сноска на dоі обязательна

\section{Право и политика $3(183) \cdot 2015$}

нее его опубликовать? Можно ли при отборе соискателей применять дополнительные критерии, помимо ранее опубликованных? Существуют ли объективные критерии для того, чтобы оправдать большие заслуги одних кандидатов в сравнении с другими?

Наиболее важным моментом следует считать неполноценность методик оценки квалификационных характеристик соискателей. Сложно реализуемым является вопрос, какие оценочные средства следует применять для объективной и эффективной оценки интеллектуальных и личных качеств соискателей, таких как способность брать на себя ответственность в выполнении обязанностей, хладнокровие, независимость, убедительность, чувствительность, коммуникабельность, честность, способность сотрудничать?

Необходимо иметь в виду, что деловые качества соискателей являются динамичными, а представленные характеристики и прочие рекомендации могут уже не отражать в силу их статичности профессиональные данные конкурсанта. В итоге не исключается, что назначенным окажется «плохой» судья. В зарубежной литературе отмечается, что даже если все рекомендации и характеристики изучены, «“звездное” резюме не обязательно показывает отличный аналитический ум или первого класса судебное мастерство» [13].

Нельзя полностью исключить из конкурсного отбора политическое влияние. Помимо того, что влияние, как со стороны ветвей власти, так и со стороны иных политических институтов, оказывается посредством самих членов отборочной комиссии, нельзя забывать и о конечном этапе анализируемого метода, где назначение осуществляет публичный (политический) субъект.

Анализ зарубежных практик показывает, что предпринимаются меры в отношении модификации метода отбора судей на основании заслуг. В числе таких мер: улучшение состава членов отборочных комиссий, гарантирующих беспристрастный отбор, без вмешательства политических сил; внесение определенности в профессиональные критерии отбора кандидатов; формирование эффективных методов оценки кандидатов и возможность оспорить оценку комиссии в судебном порядке.

Обозначенный круг проблем свойственен и российской модели конкурсного отбора кандидатов в судьи [14]. При их решении полезно использовать лучшие практики, существующие в зарубежных правовых системах отбора на основании заслуг.

\section{Библиография:}

1. Ван Чжихуа, Фоков А. П. Судебная власть в Китайской Республике // Российское правосудие. - 2012. - № 6.

2. Давид Р., Жоффре-Спинози К. Основные правовые системы современности / пер. с фр. В. А. Туманова. - М., 2009.

3. Клеандров М. И. Международные объединения судей // Российское правосудие. - 2013. - № 5.

4. Модернизация статуса судьи: современные международные подходы / отв. ред. Т.Н. Нешатаева. - М., 2011.

5. Судебная власть / под ред. И. Л. Петрухина. - М., 2003.

6. Celeste, Mary A. The Debate over the Selection and Retention of Judges: How Judges Can Ride the Wave // Court Review: The Journal of the American Judges Association. - 2010. - Vol. 46.

7. Kiley D. Merit selection of California judges / University of the Pacific. McGeorge School of Law. Institute for Legislative Practice. March 2, 1999.

8. Michael R. Dimino. The Futile Quest for a System of Judicial "Merit" Selection, 67 ALB. L. REV. 803,803 n.3 (2004).

9. Patricia Noonan. Salīdzinošais ziṇojums: Tiesnešu atlases, amatā iecelšanas un paaugstināšanas kritēriji Latvijā. Tieslietu ministrijas un ANO Attīstības programmas projekts «Atbalsts tiesu sistēmai». - Rīga, 2003.

10. Thomas R. Phillips. The merits of merit selection // Harvard Journal of Law \& Public Policy. - 2009. - Vol. 32. - N. 1.

\section{References (transliterated):}

1. Van Chzhikhua, Fokov A. P. Sudebnaya vlast’ v Kitaiskoi Respublike // Rossiiskoe pravosudie. - 2012. - № 6.

2. David R., Zhoffre-Spinozi K. Osnovnye pravovye sistemy sovremennosti / per. s fr. V. A. Tumanova. - M., 2009.

3. Kleandrov M. I. Mezhdunarodnye ob”edineniya sudei // Rossiiskoe pravosudie. - 2013. - № 5.

4. Celeste, Mary A. The Debate over the Selection and Retention of Judges: How Judges Can Ride the Wave // Court Review: The Journal of the American Judges Association. - 2010. - Vol. 46.

5. Kiley D. Merit selection of California judges / University of the Pacific. McGeorge School of Law. Institute for Legislative Practice. March 2, 1999.

6. Michael R. Dimino. The Futile Quest for a System of Judicial "Merit" Selection, 67 ALB. L. REV. 803,803 n.3 (2004).

7. Patricia Noonan. Salīdzinošais ziņojums: Tiesnešu atlases, amatā iecelšanas un paaugstināšanas kritēriji Latvijā. Tieslietu ministrijas un ANO Attīstības programmas projekts «Atbalsts tiesu sistēmai». - Rīga, 2003.

8. Thomas R. Phillips. The merits of merit selection // Harvard Journal of Law \& Public Policy. - 2009. - Vol. 32. - N. 1. 